\title{
Spatiotemporal Evolution and Influencing Factors of Ecological Civilization Construction in China
}

\author{
Mei Gai, ${ }^{1}$ Xiuqi Wang $\left(\mathbb{D}^{1}{ }^{1}\right.$ and Changli Qi $\mathbb{D}^{2}$ \\ ${ }^{1}$ Marine Economy and Sustainable Development Research Center, Liaoning Normal University, Dalian 116029, Liaoning, China \\ ${ }^{2}$ Jilin Normal University, 1301 Haifeng Street, Tiexi District, Siping, Jilin 136000, China
}

Correspondence should be addressed to Xiuqi Wang; 1059883998@qq.com and Changli Qi; 13804210@qq.com

Received 26 August 2020; Revised 22 September 2020; Accepted 23 September 2020; Published 16 October 2020

Academic Editor: Jun Yang

Copyright ( $\odot 2020$ Mei Gai et al. This is an open access article distributed under the Creative Commons Attribution License, which permits unrestricted use, distribution, and reproduction in any medium, provided the original work is properly cited.

\begin{abstract}
The construction of an ecological civilization is a strategic idea proposed based on the conditions of different countries and the laws governing social development. It is a new way to promote harmonious coexistence between humans and nature. Therefore, exploring the evolution characteristics and influence of ecological civilization in China is helpful for the country's future development. This study uses the pentagon model, panel threshold regression model, and spatial analysis tool to explore the law of space-time differentiation and analyze regional coordination and ecological civilization construction in 31 provinces, cities, and autonomous regions in China from 2000 to 2018. During the study period, the construction of ecological civilization in China generally fluctuated; the spatial differentiation pattern of the eastern region was more developed than that of the central region, which was more developed than that of the western region. The regional coordination degree decreased in the order of east $>$ central > northeast $>$ west, and the degree of coordination in provinces and cities gradually shifted and finally accumulated to be reflected in the economy and environment in 2018. The most important factor affecting the development of ecological civilization was determined to be scientific research, followed by air quality and government information disclosure.
\end{abstract}

\section{Introduction}

In the middle of the $20^{\text {th }}$ century, to improve the living standards, many countries entered into a development phase aimed at vigorously pursuing economic growth, which caused environmental problems such as global warming, shortage of freshwater resources, and air pollution. Although most developed countries have implemented pollution control strategies to address these problems, there is a lack of such measures in China. Thus, China faces greater environmental challenges than other countries. Therefore, exploring the development of ecological civilization construction will not only help improve economic and social development but also greatly enhance the international status of China.

In the early days of reforms and opening-up, the Communist Party of China (CPC) proposed to balance the economic and environmental development and added the concept of sustainable development in the reports of the $15^{\text {th }}$ and $16^{\text {th }}$ National Congress of the CPC, which advocated the coordinated development of the ecological environment with the economy, society, institution, and culture. The concept of ecological civilization construction was first proposed as a major development strategy in the $17^{\text {th }} \mathrm{Na}$ tional Congress of the CPC. In the report of the $18^{\text {th }}$ National Congress, the CPC further elaborated that "building an ecological civilization is a long-term and grand plan that concerns the well-being of the people and the future of the nation" [1]. In the Fifth Plenary Session of the $18^{\text {th }}$ CPC Central Committee, strengthening the level of ecological civilization was added to the national five-year plan for the first time, and the report of the $19^{\text {th }}$ National Congress of the $\mathrm{CPC}$ reaffirmed the establishment of the socialist ecological civilization.

The connotation of the construction of ecological civilization has been proposed in both a broad and specific sense. In the broad sense, the construction of ecological civilization is a systems engineering approach that integrates the economic, political, cultural, and social construction systems to save natural resources and protect the 
environment $[2,3]$. In the specific sense, it involves improving relationships between humans and nature, treating nature with a civilized and rational attitude, opposing the extensive use of resources, and building and protecting the ecological environment [4]. Therefore, we should achieve the coordinated development of man and nature, resources and economy, and environment and society. We should also realize the protection of the ecological environment and sustainable utilization of resources by constructing a "green economy" and a "green society." Based on these definitions, this study summarizes the broad and narrow connotations of the construction of ecological civilization. The core of this idea comprises social, environmental, economic, cultural, and institutional construction as a whole, emphasizing the need for coordination among them.

At present, most researches on sustainable development $[5,6]$, with construction of ecological civilization, a component of it, mainly focuses on the associated evaluation system and research methods and approaches. (1) A consensus regarding the evaluation system of ecological civilization construction has not yet been arrived at by scholars and can be roughly divided into three approaches. The first type involves evaluating the construction of ecological civilization from three levels of society, economy, and nature [7-9]. For example, Mi et al. [10] took the three systems of "society-economy-nature" as a theoretical basis to construct an evaluation system of ecological civilization construction with the model of "pressure-state-response." The second approach is mainly based on the content of the Measures for Evaluation and Assessment of Ecological Civilization Construction Objectives, of which the system incorporates seven aspects: resource utilization, environmental governance, environmental quality, ecological protection, growth quality, green life, and public satisfaction [11]. The third approach involves the integration of the first two. Some of the indicators are selected for targeted evaluation studies. For example, Deng et al. [12] and others set up an evaluation system comprising the four levels of territorial space, resources, ecological environment, and the system as a whole, and $\mathrm{Bi}$ et al. [13] evaluated the construction of ecological civilization from the four aspects of land space, resources and environment, economy and society, and system guarantee. (2) Research methods can be divided into three groups: evaluation method, regional coordination, and influencing factors. The evaluation methods include coefficient of variation [14], pressure-state-response (PSR) model [15], backpropagation (BP) neural network model [16], slacks-based measure (SBM) model with undesired outputs [17], and the double-benchmark progressive method [18]. (3) The study of regional coordination can be divided into two parts: regional coordination and intraregional system coordination. Zhang et al. [19] used the data envelopment analysis (DEA) method to analyze the coordination degree of regional ecological civilization construction in China. Feng et al. [20] conducted a coordinated study on the environment, economy, society, and institutional components of ecological civilization construction in Hebei Province using the principle of coefficient of variation. The influencing factors were determined using factor analysis [21], regression models [22], and spatial econometric models [23]. Most existing studies focus on the construction of a certain type of ecological civilization or analyze a certain aspect from the perspective of ecological civilization. For example, Zhong et al. [24] used the method of systematic review to compare the data on ecotourism in China from 1992 to 2015. Ren et al. [25] integrated ecological civilization into university education and established a comprehensive evaluation system of ecological civilization education in colleges and universities. Wang et al. [26] analyzed the significance, status, and problems of agricultural green development in China based on the development of ecological civilization by reviewing relevant literature.

To sum up, based on the existing research, this paper reconstructs a reasonable and scientific evaluation system of ecological civilization construction. Based on the current literature, the legal index is added at the system level, and according to the overall development status, the cultural system is added to the original system, with cultural and intangible heritage, education level, and other indicators added to fill it. Finally, the construction of ecological civilization is divided into society, environment, economy, culture, and system to define the basic connotation of China's ecological civilization construction. The paper discusses the spatiotemporal evolution of ecological civilization construction and explores the degree of coordination and deviation between regions and systems within regions using the pentagon model for the first time. The panel threshold model is used to analyze the influencing factors, which can be used as a reference for promoting the socialist modernization of China.

\section{Methods}

2.1. Construction of Index System and Data Sources. Based on the core of ecological civilization construction and with reference to the existing research findings [7-13], the reports of the $18^{\text {th }}$ and $19^{\text {th }}$ National Congress of the CPC, and the national assessment methods for ecological civilization construction objectives, we regrouped the indicators of land space, resource utilization, environmental governance, environmental quality, ecological protection, growth quality, green life, and public satisfaction into social, environmental, economic, and institutional systems. The social system includes indicators such as regional urbanization, population, infrastructure construction, and medical treatment and covers green living, consumption, and service level. The environmental system reflects the influence of regional development on the local ecological environment, including air quality, environmental protection, and emissions control and treatment. The economic system covers aspects such as the quality of growth and industrial structure. To balance the pace and quality of economic development in the construction of ecological civilization, two indicators were added to measure economic consumption: water and energy consumption per unit gross domestic product (GDP). Since the institutional system is limited to the market level, legal indicators, such as crime rate, local legislation, and the number of corrupt individuals, were 
incorporated to form a new system. As the construction of ecological civilization entails the coordinated development of a complex and pluralistic system, new indicators such as national heritage, world cultural heritage, national cultural unit, education level, and the number of libraries were added to construct a cultural system to measure the degree of regional civilization. Finally, an index was constructed with five subsystems: social development, green environment, economic growth, cultural heritage, and institutional system (Table 1).

Considering the availability of data, this study was conducted in 31 provinces, cities, and autonomous regions in China (except Hong Kong, Macao, and Taiwan) from 2000 to 2018. The data were obtained from the statistical almanac of local government network, national environmental statistics bulletin, statistical yearbook of provinces and cities, China statistical yearbook on enviroment [27], China's environmental yearbook [28], law yearbook of China [29], and procuratorial yearbook of China [30].

\subsection{Research Methods}

2.2.1. Evaluation Method. Based on the current research on the evaluation systems of ecological civilization construction $[12,13]$, this study adopted the improved entropy TOPSIS method [31,32] to carry out subjective weighting [33] and objective weighting and used the ecological index $(I)$ and subsystem indices $(S, E, G, C, H)$.

2.2.2. Pentagon Model. In the pentagon model, the sum of the distances from any point to the vertices is a fixed value, which can directly and concisely reflect the relationship between different elements and the degree of coordination and deviation of a single element index. As shown in Figure 1, the pentagon is a regular pentagon. The five sides represent the indicators of social development, green environment, economic growth, cultural heritage, and institutional systems. The dimensionless results of spatial elements ( $\mathrm{Si}, \mathrm{Ei}, \mathrm{Gi}, \mathrm{Ci}$, and $\mathrm{Hi}$ ) represent the vertical distances to the five sides of society, environment, economy, culture, and institutional system, respectively, and satisfy the condition $\mathrm{Si}+\mathrm{Ei}+\mathrm{Gi}+\mathrm{Ci}+\mathrm{Hi}=1$ to determine its coordinates (points of ecological civilization). The vertices of this regular pentagon are connected to the vertices of five different regions. Among those regions, I is the advantage type of social development, II is the advantage type of green environment, III is the advantage type of economic growth, IV is the advantage type of cultural heritage, and V is the advantage type of the institutional system. The coordination and deviation degrees can be further defined by evaluating the type of spatial unit.

2.2.3. Panel Threshold Regression Model. Using the panel regression model to evaluate the influence of each index on the construction of ecological civilization, this study adopts the threshold regression model proposed by Hansen. Taking social development, green environment, economic growth, cultural heritage, and institutional system as the threshold variables, this study further analyzes their nonlinear relationship with the construction of ecological civilization (the relationship between variables varies significantly) [34].

Panel Regression Model. In this study, the panel regression model was used as the basic model. The model assumptions are as follows:

$$
\begin{aligned}
Q_{i t}= & \alpha_{0}+\alpha_{1} X_{1 i, t}+\alpha_{2} X_{2 i, t}+\cdots \cdots+\alpha_{n} X_{n i, t}+ \\
& \beta_{1} S_{i, t}+\beta_{2} E_{i, t}+\beta_{3} G_{i, t}+\beta_{4} C_{i, t}+\beta_{5} H_{i, t}+\varepsilon_{i, t},
\end{aligned}
$$

where $Q_{i, t}$ is the ecological index, $X_{1}, X_{2}, \ldots, X_{n}$ are the control variables, $S_{i, t}$ is the social development, $E_{i, t}$ is the green environment, $G_{i, t}$ is the economic growth, $C_{i, t}$ is the cultural heritage, $H_{i, t}$ is the institutional system, $\varepsilon_{i, t}$ is the corresponding coefficient vector, $i$ refers to the province, and $t$ is the year.

Threshold Regression Model. In this study, social development, green environment, economic growth, cultural heritage, and institutional system are assumed to have an impact on the construction of ecological civilization. These are not simple linear relationships, assuming that there is a threshold value. The ecological index $(Q)$ is defined as the explanatory variable; social development $(S)$, green environment $(E)$, economic growth $(G)$, cultural heritage $(C)$, and institutional system $(H)$ are defined as the threshold variables; and the control variables are composed of $X_{1}$, $X_{2}, \ldots, X_{n}$. The specific model assumptions are shown in the following equation:

$$
\begin{aligned}
Q_{i t}= & \mu_{i}+\alpha_{1} X_{1 i, t}+\alpha_{2} X_{2 i, t}+\cdots \cdots+\alpha_{n} X_{n i, t} \\
& +\beta_{1} S_{i, t} \cdot I\left(S_{i, t} \leq \gamma_{1}\right)+\beta_{2} S_{i, t} \cdot I\left(\gamma_{1}<S_{i, t} \leq \gamma_{2}\right)+\cdots \cdots \\
& +\beta_{n} S_{i, t} \cdot I\left(\gamma_{n-1}<S_{i, t} \leq \gamma_{n}\right)+\beta_{n}+S_{i, t} \cdot I\left(S_{i, t}>\gamma_{n}\right)+\varepsilon_{i, t},
\end{aligned}
$$

where $\mu_{i}$ represents unobservable factors reflecting the construction of ecological civilization, $I(\cdot)$ is the index function, $\gamma_{1}, \gamma_{2}, \ldots, \gamma_{n}$ are the threshold values to be estimated, $S$ can be replaced by $E, G, C$, and $H$, and the other variables are equivalent to equation (1).

\section{Results}

\subsection{Analysis of Space-Time Characteristics and Regional Coordination Degree of Ecological Civilization Construction in China}

3.1.1. Analysis of Space-Time Changes in Ecological Civilization Construction in China. The ecological index of China (Figure 2) increased from 12.51 to 14.17 from 2000 to 2018. During this period, the average annual growth rate was $9.22 \%$ and the overall development pattern was environment $>$ society >economy >institution >culture. These results suggest that society, economy, system, and culture are important components in the development of ecological civilization, and the environment is the decisive factor 
TABLE 1: Evaluation index system of ecological civilization construction.

\begin{tabular}{|c|c|c|c|}
\hline Target layer A & Subsystem layer & Index layer & Unit \\
\hline \multirow{40}{*}{$\begin{array}{l}\text { Construction of ecological } \\
\text { civilization }\end{array}$} & \multirow{12}{*}{ Social development } & Urbanization rate & $\%$ \\
\hline & & Urban unemployment registration rate & $\%$ \\
\hline & & Population density ${ }^{1}$ & Person $/ \mathrm{km}^{2}$ \\
\hline & & Proportion of working-age population ${ }^{2}$ & $\%$ \\
\hline & & Road person ratio & $\mathrm{m}^{2}$ \\
\hline & & Annual electricity consumption per capita & Billion kwh \\
\hline & & Consumption level of residents & Yuan/person \\
\hline & & Per capita level of medical care & - \\
\hline & & Acreage per capita & $10000 \mathrm{~m}^{2}$ \\
\hline & & Proportion of environmental investment & $\%$ \\
\hline & & Municipal sewage treatment rate & $\%$ \\
\hline & & Waste disposal rate & $\%$ \\
\hline & \multirow{6}{*}{$\begin{array}{l}\text { Green } \\
\text { environment }\end{array}$} & $\begin{array}{l}\text { Comprehensive utilization rate of industrial solid } \\
\text { waste }\end{array}$ & $\%$ \\
\hline & & $\mathrm{SO}_{2}$ emission rate per unit of GDP & $\%$ \\
\hline & & Air quality & $\mu \mathrm{g} / \mathrm{m}^{3}$ \\
\hline & & Proportion of ecological area ${ }^{3}$ & $\%$ \\
\hline & & Per capita area of public green space & $\mathrm{m}^{2} /$ person \\
\hline & & Per capita water resources & $\mathrm{m}^{3} /$ person \\
\hline & \multirow{9}{*}{ Economic growth } & GDP per capita & Yuan \\
\hline & & Ratio of secondary production & $\%$ \\
\hline & & Ratio of tertiary production & $\%$ \\
\hline & & Tourist foreign exchange & Million dollars \\
\hline & & Input intensity of R\&D investment & $\%$ \\
\hline & & Water consumption per unit of GDP & $\mathrm{m}^{3} / 10000$ yuan \\
\hline & & Energy consumption per unit of GDP & $\begin{array}{l}\text { Ton standard coal/ } \\
10,000\end{array}$ \\
\hline & & Public budget revenue per capita & Billion \\
\hline & & Investment in real estate development & Billion \\
\hline & \multirow{7}{*}{ Cultural heritage } & National intangible cultural heritage numbers & - \\
\hline & & State-level cultural relic unit & - \\
\hline & & The world's intangible cultural heritage numbers & - \\
\hline & & World cultural heritage & - \\
\hline & & Education level & - \\
\hline & & Library numbers & - \\
\hline & & Cultural scenic spot numbers & - \\
\hline & \multirow{6}{*}{$\begin{array}{l}\text { Institutional } \\
\text { system }\end{array}$} & Safety accident & - \\
\hline & & Crime rate & $\%$ \\
\hline & & Corrupt person numbers & Person \\
\hline & & Local legislation numbers & - \\
\hline & & Government disclosure numbers & - \\
\hline & & Public engagement & - \\
\hline
\end{tabular}

${ }^{1}$ The population density refers to the ratio of the regional population to the land area. ${ }^{2}$ The proportion of the working-age population refers to the ratio of the number of people aged 15-64 to the total population. ${ }^{3}$ The proportion of the ecological area refers to the ratio of the local natural environment protection area to the total area under jurisdiction.

restricting the development of ecological civilization. The period of 2000-2018 can be divided into three stages (Figure 2):

The first stage (2000-2006) is termed the growth stage, when the ecological index growth rate was high $(13.28 \%)$, indicating the development pattern of environment > economy > society >institution >culture. However, it fluctuated greatly in this stage as the concept of ecological civilization had not yet been put forward in the "tenth fiveyear plan." Although the annual per capita GDP growth rate was $13.88 \%$, focus was limited to the rapid development of the economy, ignoring environmental pollution, energy consumption, and the unstable situation of system development. In 2004, compared with the previous year, the crime rate and the amount of corruption increased by $1 \%$, and the system index decreased, causing the ecological index to reach its lowest point.

The second stage (2007-2012) represents the transitional stage, in which China's economic development was growing at a high speed and the GDP per capita was growing at an annual rate of $13.88 \%$. However, this extensive economic growth caused heavy environmental pollution and resource wastage, and the growth rate of the ecological index decreased by $10.5 \%$. The development pattern changed from that during the first stage to environment $>$ society $>$ economy >institution $>$ culture. During this stage, the $17^{\text {th }}$ 


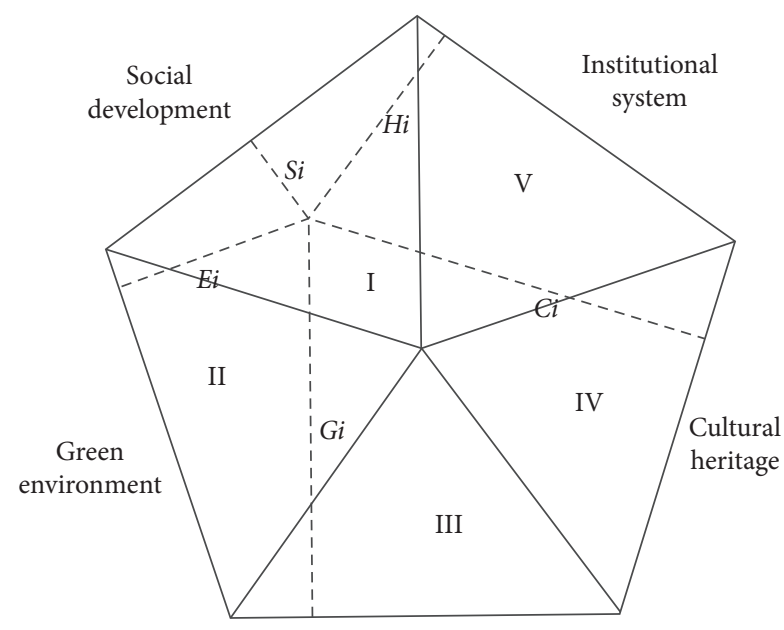

Economic growth

FIGURE 1: Schematic diagram of the pentagon model of the system of society, environment, economy, culture, and institution.

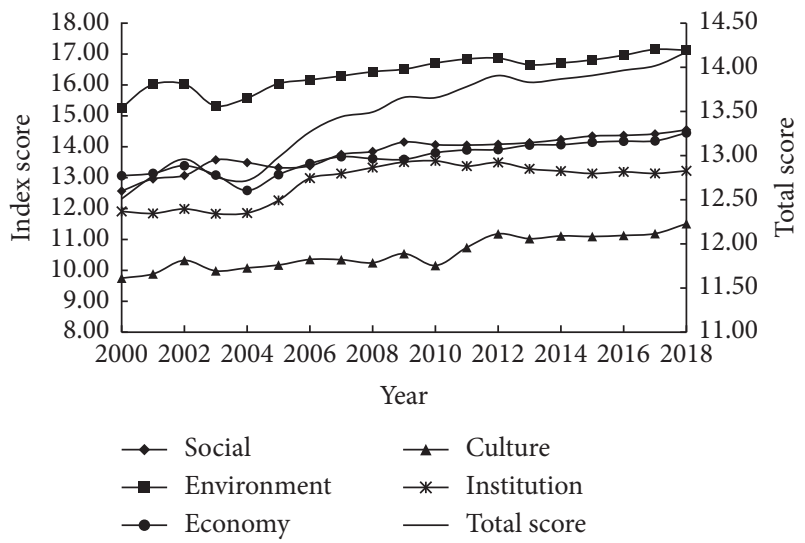

Figure 2: Change in China's ecological index (2000-2018).

National Congress of CPC formulated an industrial structure, economic growth pattern, and consumption pattern to save resources and energy and protect the ecological environment. This stage also coincided with the 2008 global financial crisis, which affected economic development by slowing the growth rate slightly. This period was also characterized by accelerated social development that improved people's livelihood and ensured the development of various social parameters such as education, medical care, and social security.

The third stage (2013-2018) is the stage of development and stability, with the development pattern unchanged. The annual growth rate of the ecological index was only $5.66 \%$. The $18^{\text {th }}$ National Congress of the CPC was held during this period and China's green, low-carbon economic model achieved the initial results, forming the basis for energy conservation and environmental protection efforts for sustainable development of the industrial structure.

The ecological index evolution in different provinces and cities in China (Figure 3) can be divided into four categories: (1) $I \geq 0.55$ : the number of developed areas increased from one in 2000 (Shanghai) to three in 2008 (Shanghai, Fujian, and Guangdong) and then to five in 2018 (Beijing, Yunnan, Shanghai, Fujian, and Guangdong) with a spatial point pattern; (2) $0.45 \leq I<0.55$ : less developed areas decreased from eight (Chongqing, Liaoning, Hainan, Guangxi, Tibet, Jiangsu, Zhejiang, and Jiangxi) in 2000 and 2008 to seven (Zhejiang, Jiangsu, Guangxi, Tibet, Tianjin, Henan, and Hunan) in 2018, which were generally distributed in the eastern part of China; (3) $0.35 \leq I<0.45$ : the number of general developed areas increased from 12 in 2000 to 15 in 2008 and increased to 16 in 2018 (Sichuan, Liaoning, Inner Mongolia, Jiangxi, Shaanxi, Hubei, Chongqing, Hebei, Shandong, Shanxi, Hainan, Jilin, Anhui, Xinjiang, and Heilongjiang), which were gradually transferred to the central and western regions. Among them, the ecological index of Jilin and Liaoning decreased significantly from the less developed ecologically civilized areas in 2008 to the general areas in 2018. The ecological index of Jilin declined and the economic development and urbanization process accelerated, resulting in severe air pollution and a rapid decrease in the green environment index. (4) $I<0.35$ : the number of backward areas decreased from 10 in 2000 to 5 in 2008 and to 3 in 2018 (Gansu, Guizhou, and Ningxia).

3.1.2. Analysis of the Construction of Ecological Civilization in China. During the study period, to investigate the spacetime law of China's ecological civilization construction, social development, green environment, economic growth, cultural heritage, and the institutional system components were analyzed (Figure 4).

(1) Social development is mainly reflected in the level of regional urbanization, people's living standards, and infrastructure construction. During the study period, the developed areas as a whole were located in the eastern coastal areas, while the less developed areas showed a T-shaped distribution. In 2000, the level of social development in China was relatively low and the development patterns were scattered. With continuous economic growth, the social development patterns gradually stabilized and the social development index rose from 12.57 to 14.55 . The Beijing-Tianjin-Hebei, Jiangsu-Zhejiang, and other socially developed areas offer a good quality of life for their residents and excellent public service facilities. The urbanization rate of Beijing reached $86.5 \%$, while most of the western regions were backward areas in terms of social development, with small population density and relatively backward infrastructure. Only Xinjiang developed from a general area to a less developed area during the study period, but the social development of this area was still deficient, and the proportion of the working population increased by only $2.16 \%$ from 2000 to 2018, to some extent, restricting the population growth and affecting the development of society. Most of the central regions of China were less developed areas, which had more obvious 


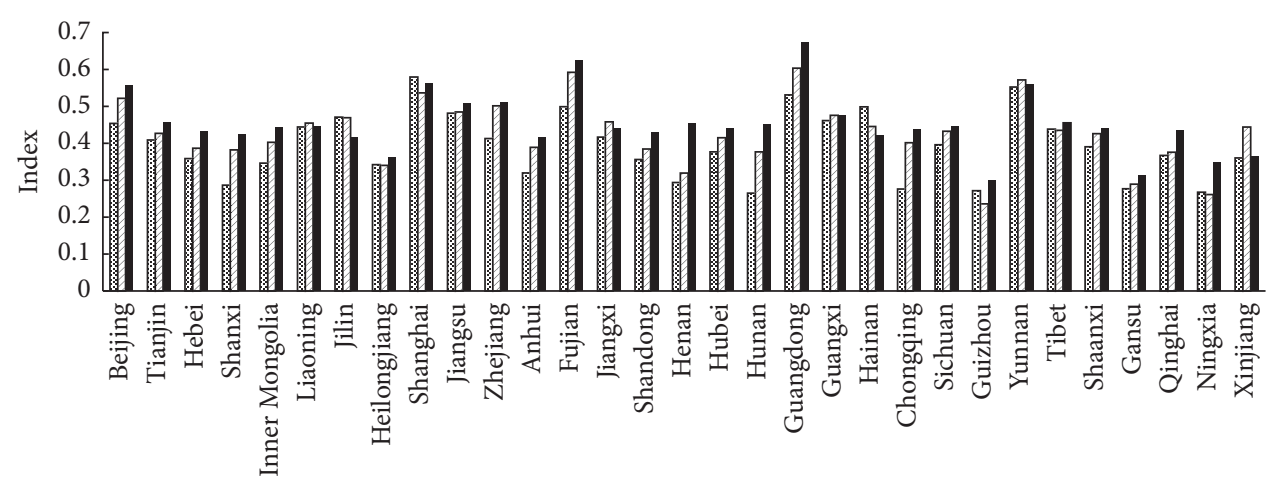

Province

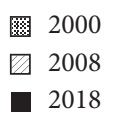

Figure 3: Spatial differentiation of China's ecological civilization construction (2000, 2008, and 2018).

changes. The urban unemployment rate decreased from $3.7 \%$ in 2008 to $3.1 \%$ in 2018 .

(2) The green environment reflects the air and water quality, pollution control, and ecological environment. The results showed that the index of environmental quality was the best during the study period, and the index increased from 15.26 to 17.13 with a decreasing spatial differentiation from west to east. In terms of the green environment, the western and southern regions of China are developed, and the regions of Beijing, Tianjin, and Hebei are backward areas. Guizhou, Chongqing, and Gansu have responded positively to state policies by revising the local laws on the protection of the ecological environment. After the state implemented actions such as greening the land, protecting the ecological red line, and controlling smog, the environmental value in these provinces increased to the median level. The environmental quality of backward areas also improved, e.g., the proportion of good air days in Beijing increased from $48 \%$ in 2013 to $65.8 \%$ in 2018 , indicating that air quality in the environmentally backward areas in China improved.

(3) Economic growth refers to a region's economic development degree, the proportion of industries, investment in science and technology funds, and economic consumption. The results show that China's economic growth index increased from 13.06 to 14.45 , showing a gradually declining trend from southeast to northwest. In 2000, China's overall economic level was relatively low and only Guangdong was a developed region. As a result of the countermeasures put forward in the "eleventh five-year plan" to "maintain stable and relatively fast economic development and speed up the transformation of the mode of economic growth," China's economic development speed has increased. In particular, in 2008, the number of developed regions rose to four, and by 2018, it had reached six, among which the Beijing-Tianjin-Hebei and southeast coastal areas were economically developed regions, and the Northwest Frontier areas such as Xinjiang and Tibet were financially backward regions. Economic growth in the central region was evident, with a GDP growth rate of $8.8 \%$ in 2018, which has shifted from a general area of economic development to a less developed level. In the early stage of reform, China vigorously developed the economy of the eastern coastal areas; however, with an increased number of policies being implemented, the center of economic development gradually shifted to the central region, forming a dual-core development model in the eastcentral region.

(4) The cultural heritage reflects people's cultural level and the inheritance of traditional culture in the region. The index of cultural heritage increased from 9.75 to 11.52 , accounting for the lowest proportion in the total index. Xinjiang, Jiangsu, Shanxi, and Beijing had high national cultural heritage index values, mostly owing to the intangible cultural heritage, such as Dingxiang County dough figurines and folk tales. Guizhou, Guangxi, Qinghai, and other places scored lower on the cultural index.

(5) The institutional system is an important prerequisite for development, which reflects the number of local laws and regulations, the degree of public participation, and the stability of the region. The institutional system index increased from 11.91 to 13.22 , which shows the trend east $>$ middle $>$ west. During the study period, the northeastern and eastern regions of China were the developed areas and Guizhou, Henan, and Hubei were the backward areas. As the regional government lagged behind the implementation of the policy, the development of 


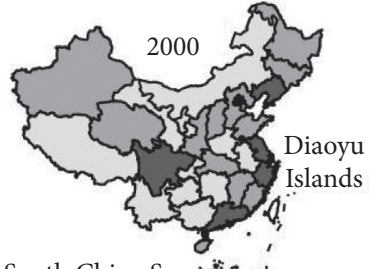

South China Sea ? $\cdots$

Social
development

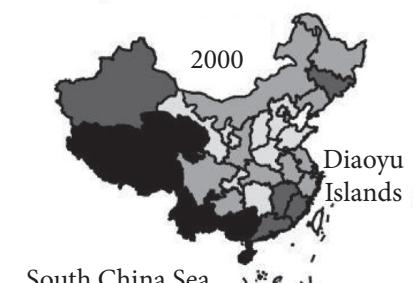

South China Sea $\quad *$. .

Green
environment

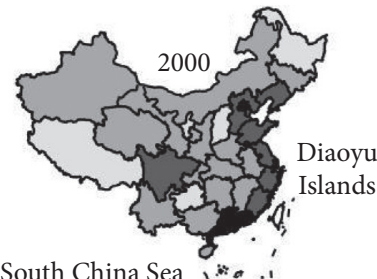

China Sea , sta
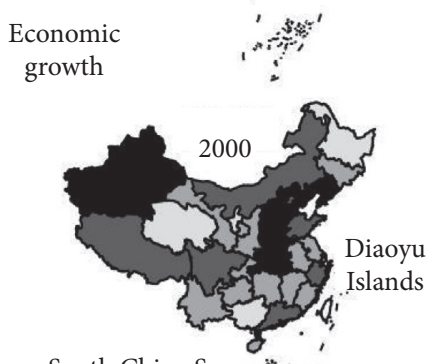

South China Sea , *...

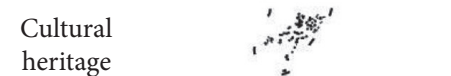
heritage

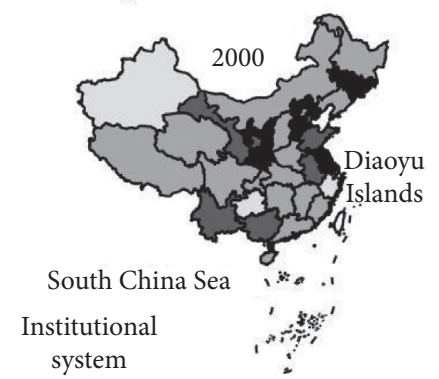

$\begin{array}{lllll}0 & 1,750 & 3,500 & 5,250 & 7,000\end{array}$

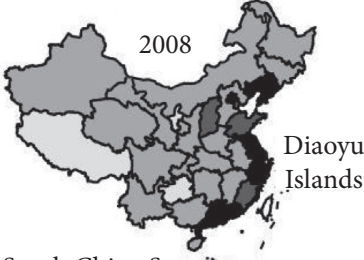

South China Sea $、 m_{*}$. .

Social
development

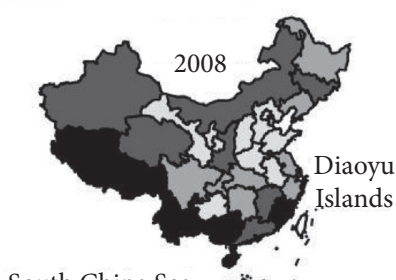

South China Sea $\therefore$...

Green

environment

, stis

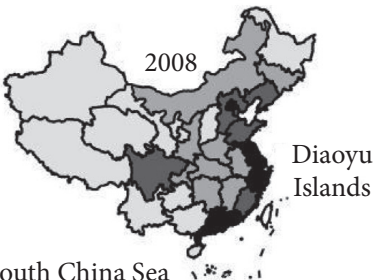

South China Sea,$*$.
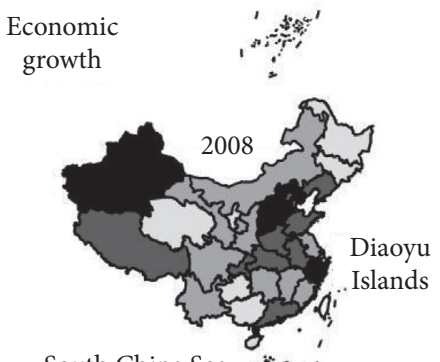

South China Sea , $\%$...

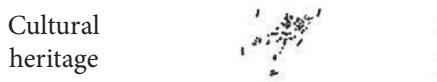

South China Sea $1 *$.

South China Sea $\quad \cdots$

Green

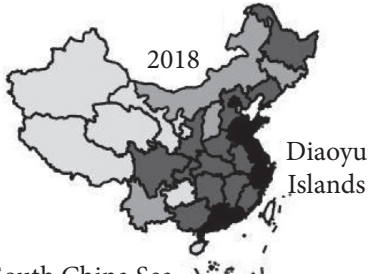

South China Sea 's".

Economic
growth
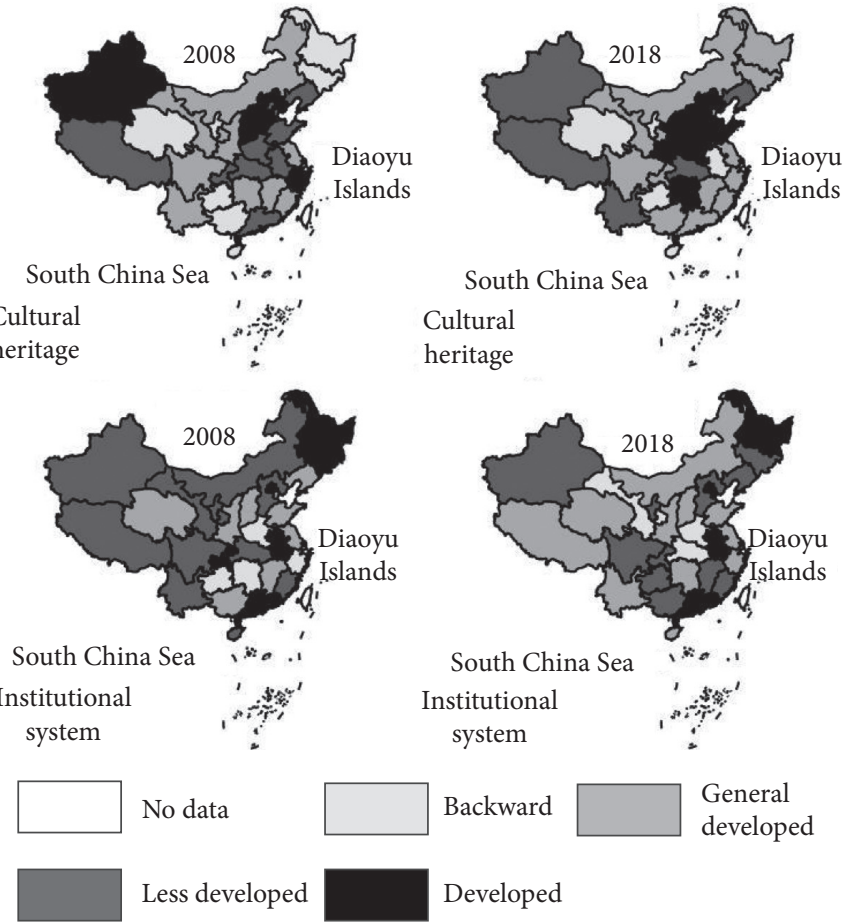

South China Sea

Institutional
system

Backward

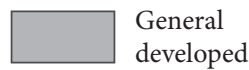

Developed

FIgURE 4: Spatial distribution development of China's ecological civilization construction (2000, 2008, and 2018).

ecological civilization construction in the provinces and cities also lagged behind. Hence, the development of the system in China needs to be further improved.
3.1.3. Analysis of the Coordination Degree of Regional Ecological Civilization Construction in China. Further analysis of the regional coordination degree of the ecological civilization construction (Figure 5) shows that the regional 


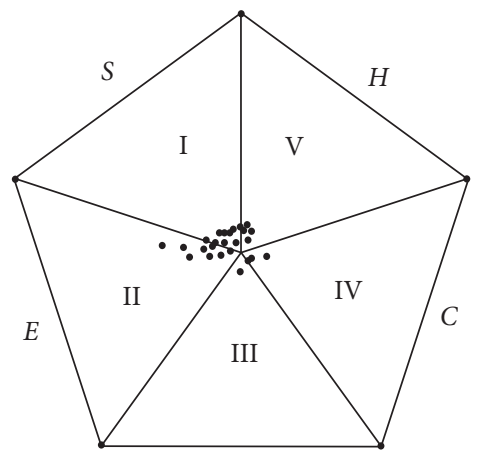

G

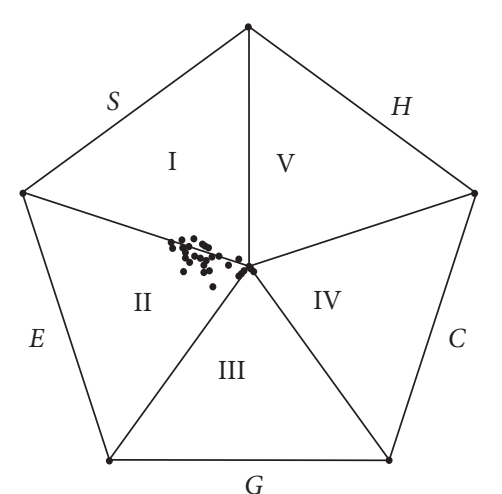

G

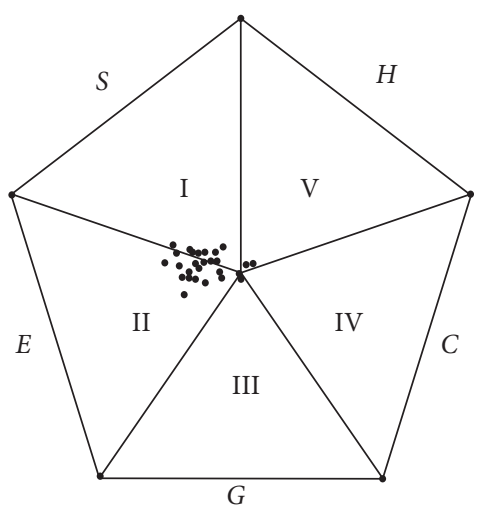

(a) 2000. (b) 2008. (c) 2018. developments of provinces and cities are not coordinated; however, there is a noticeable shrinking trend toward the center of gravity of the pentagon. The regions with poor regional coordination are the western and northeastern regions, among which the western regions, such as Qinghai and Tibet, have the highest degree of coordination and deviation from the other regions. The environmental quality and cultural level of these regions are highly developed; however, the society, economy, and institution components are relatively underdeveloped. Since the issuing of a catalog by the state council to encourage industrial development in the western regions in 2014, the development strategies for the western regions have been implemented, and the society and economy components have been strengthened. However, a small population base is still a constraint to development, especially in Tibet, where the population development density is less than $2 \%$ of the national average. In the northeast areas, Heilongjiang and Jilin have well-developed institutions, but their economic development is backward, their GDP still maintains a middle to low ranking relative to the rest of the country, and the development between the systems shows an extremely uncoordinated trend. The eastern coastal areas have the highest levels of regional coordination, followed by the central region and the southeastern coastal areas of China, which are rich in resources and have convenient transportation facilities, vast markets, and efficient policies. The levels of social, economic, institutional, and cultural development in the southeastern coastal areas are higher than the national average, and the ecological environment has improved significantly in these areas. In particular, Guangdong and Jiangsu, which gained much focus in 2018, had GDPs that ranked first and second in China. Simultaneously, their ecological environment improved, and, with a more sound system, the two places have achieved a higher degree of coordination. With the increase in time, the trend of economic development has expanded inland from the southeast coast. In $2018,50 \%$ of the provinces in the central region entered the top 10 ranks in the GDP rankings. The increased economic growth rate implies the development of society, culture, and institutions, balancing the development pattern of ecological civilization construction.
In 2000, the points of the ecological index were unevenly distributed among the five components and were dominated by the environment, society, and economy. In 2008, the degree of coordination in the region increased and the points of the provinces and cities shrank and shifted to the center of gravity. Compared with 2008, the deviation degree of each province and city in 2018 decreased slightly, and the coordination was better. Although some provinces and cities gathered in the center of gravity, most provinces and cities still deviated from the environment-society, which may be due to the increasingly fierce trade friction between China and the United States in 2018. China's high-end manufacturing development and economic growth have been affected to a certain extent, resulting in a slightly lower economic index than in previous years. Moreover, with the promulgation of the "Environmental Protection Tax Law" and the new version of the "Law on the prevention and control of Water Pollution," the protection of the environment and water resources was strengthened. Therefore, most of the ecological civilization points were concentrated within the regions of environment and society.

In 2000-2018, the province that exhibited less fluctuation was Ningxia. Ningxia is highly uncoordinated and has a high degree of deviation, and only the green environment in this area has developed well. Ningxia experiences a long-term drought and has a harsh ecological environment. In 2018, the total output value of Ningxia was 165.026 billion yuan, $4 \%$ of that of Jiangsu Province. The economic level was relatively low, the social conditions were backward, and the development level of per capita medical treatment level was average. Beijing had a large fluctuation range. In 2000, economic growth was the dominant component in Beijing. In 2008, the point representing Beijing in the pentagon model was close to the economic growth component; however, the green environment component remained dominant, and this dominance was maintained in 2018. This transition path is caused by Beijing's role as the center of China's economic exchange; its per capita GDP is the second highest in China. However, it experienced a shortage of water resources, high levels of smog, and other 
environmental problems, and it was only after optimizing the industrial structure and increasing the proportion of scientific and technological input that the environmental quality improved and the city moved toward the green environment.

\subsection{Analysis of Influencing Factors}

3.2.1. Panel Data Regression Results. In this study, we tested the panel data from 2000 to 2018 in China. All the variables passed the 5\% significance level test; thus, the original hypothesis of the existence of the unit root was strongly rejected, i.e., the original sequence is stable. On this basis, panel data models were built using all the indicators of China's ecological civilization and the results of the $1 \%$ significance test.

The results in Table 2 show that the F statistic is significant. Thus, the fixed-effect models without heteroscedasticity and mixed ordinary least squares (OLS) models were excluded. The Hausman test was used to confirm that the $p$ value is less than 0.1 and the random effects model was used.

Population density (PD) and cultural heritage did not pass the significance test, except for the green environment. Other indicators were positive, as the rapid expansion of PD resulted in a sharp decline in the local carrying capacity. The shortage of resources aggravated the contradiction between environment and population, which had a negative impact.

The correlation coefficients between the consumption level of residents (CLR) and all indexes were positive, and the CLR was affected by the overall economic situation to a great extent. In general, when the economy grows, the level of consumption rises, and the living standards improve, which otherwise decline.

The correlation coefficient between the proportion of environmental investment (PPI) and the construction of ecological civilization was not significant. Except for the economy, the other indexes were all positive, and the environmental index was the most influential. The reason for this is that ecological protection investment is one of the crucial measures of the state to control the ecological environment, it plays an important role in environmental governance, and it reflects the level of social and economic development.

The correlation coefficient between air quality $(\mathrm{AQ})$ and all indicators was positive. AQ had a more significant impact on the development of ecological civilization. Haze pollution significantly impacts the air quality in China; smog accelerates the deterioration of the environment, causes visual impairment, hinders the normal operation of the transportation industry, and affects social and economic activities.

Technology input (IST) was not significantly correlated with cultural heritage; however, it was positively and significantly related to the other indices. Government-led investments in the science and technology sector can improve the production efficiency, enhance the utilization of resources, and promote the development of a green economy while reducing the emissions of environmental pollutants.

Energy consumption (EC) had a tremendous and negative influence on the development of China's ecological civilization construction. Although China is rich in energy resources, the per capita ownership is low, and the spatial distribution is unbalanced. At the same time, the excessive consumption of energy will aggravate the problems of resource shortage and environmental pollution, leading to economic decline and social development stagnation.

World nonheritage quantity (WCQ) was positively and significantly correlated with all the indicators. The World Intangible Cultural Heritage is a manifestation of China's long cultural heritage, which has a varying degree of impact on all aspects of China's development. By the end of 2018, China had 40 world intangible cultural heritages, ranking first in the world.

The relationship between educational attainment (EL) and the construction of ecological civilization was not significant. Except for the green environment, the other indicators showed significant positive correlations; this may be because education is essential for social development in China, and the increase of high-quality technical talents can provide an impetus for the development of China's economy. However, the rapid growth of the economy and society may destroy China's energy structure, increase the emission of pollutants, and have a particularly negative impact on the environment.

Environmental Regulation (ER) was negatively related to economic growth only, and the other indicators were positively and significantly related. Through the introduction of rational ecological planning, we can improve the quality of the environment, reduce the waste of resources, and promote a better-coordinated development of our society and environment. However, the economic structure of provinces and cities that depend on energy resources will be impacted after the promulgation of the Environmental Regulations for Sustainable Development, affecting local economic development.

The government information disclosure state (GCS) was significantly related to all indicators at the $1 \%, 5 \%$, and $10 \%$ level and only negatively associated with economic growth, which may be because the information issued by the government restricted economic development to a certain extent.

\subsubsection{Empirical Study on Threshold Effect and Analysis of} Results. We used $S, E, G, C$, and $H$ as threshold variables to test their stage effects on the construction of ecological civilization. Using the threshold model requires two verification steps. The first step is the threshold existence test, which determines whether the threshold effect is significant. $F$ statistics, $p$ values, and the critical values of $1 \%, 5 \%$, and $10 \%$ were obtained by bootstrapping 500 times. The existence test of the model threshold shows the threshold effects on ecological civilization construction under the respective functions of social development, green environment, 
TABLE 2: Panel regression model results.

\begin{tabular}{|c|c|c|c|c|c|c|}
\hline & Model 1 & Model 2 & Model 3 & Model 4 & Model 5 & Model 6 \\
\hline Explanatory variable & $Q$ & $S$ & $E$ & $G$ & $C$ & $H$ \\
\hline $\mathrm{PD}$ & $\begin{array}{l}0.0176^{* * *} \\
(0.001162)\end{array}$ & $\begin{array}{c}0.0045^{* * * *} \\
(0.0018)\end{array}$ & $\begin{array}{c}-0.0025^{* * *} \\
(0.0015)\end{array}$ & $\begin{array}{c}0.0062^{* * *} \\
(0.0015)\end{array}$ & $\begin{array}{c}0.0805 \\
(0.0167)\end{array}$ & $\begin{array}{c}0.0447^{* * * *} \\
(0.0015)\end{array}$ \\
\hline CLR & $\begin{array}{c}0.0050^{* * *} \\
(0.00073)\end{array}$ & $\begin{array}{c}0.0015^{* * *} \\
(0.0014)\end{array}$ & $\begin{array}{c}0.0281^{* * *} \\
(0.0177)\end{array}$ & $\begin{array}{c}0.0031^{* * *} \\
(0.0112)\end{array}$ & $\begin{array}{c}0.0021^{* * * *} \\
(0.0013)\end{array}$ & $\begin{array}{c}0.0259^{* * * *} \\
(0.0114)\end{array}$ \\
\hline PPI & $\begin{array}{c}0.0056 \\
(0.0025)\end{array}$ & $\begin{array}{c}0.0219^{* * *} \\
(0.0061)\end{array}$ & $\begin{array}{c}0.0980^{* * *} \\
(0.0518)\end{array}$ & $\begin{array}{c}-0.0067^{* * *} \\
(0.0496)\end{array}$ & $\begin{array}{c}0.0025^{* * *} \\
(0.0057)\end{array}$ & $\begin{array}{c}0.0025^{* * *} \\
(0.0051)\end{array}$ \\
\hline AQ & $\begin{array}{c}0.0137^{* * *} \\
(0.0004)\end{array}$ & $\begin{array}{c}0.0148^{* * *} \\
(0.0098)\end{array}$ & $\begin{array}{c}0.2223^{* * *} \\
(0.0835)\end{array}$ & $\begin{array}{c}0.1042^{* * *} \\
(0.0799)\end{array}$ & $\begin{array}{c}0.0055^{* * *} \\
(0.0912)\end{array}$ & $\begin{array}{c}0.0102^{* * *} \\
(0.0081)\end{array}$ \\
\hline IST & $\begin{array}{c}0.1919^{* * *} \\
(0.0409)\end{array}$ & $\begin{array}{c}0.0290^{* * *} \\
(0.0101)\end{array}$ & $\begin{array}{c}0.0194^{* * *} \\
(0.0086)\end{array}$ & $\begin{array}{c}0.0658^{* * *} \\
(0.0819)\end{array}$ & $\begin{array}{c}0.0248^{* * *} \\
(0.0934)\end{array}$ & $\begin{array}{c}0.0669^{* * *} \\
(0.0832)\end{array}$ \\
\hline EC & $\begin{array}{c}-0.1246^{* * *} \\
(0.0376)\end{array}$ & $\begin{array}{c}-0.0032^{* * *} \\
(0.0093)\end{array}$ & $\begin{array}{c}-0.1797^{* * *} \\
(0.0786)\end{array}$ & $\begin{array}{c}-0.1514^{* * *} \\
(0.0075)\end{array}$ & $\begin{array}{c}-0.1574^{* * *} \\
(0.0086)\end{array}$ & $\begin{array}{c}-0.1026^{* * *} \\
(0.0765)\end{array}$ \\
\hline WCQ & $\begin{array}{c}0.0119^{* * *} \\
(0.0036)\end{array}$ & $\begin{array}{c}0.0328^{* * *} \\
(0.0876)\end{array}$ & $\begin{array}{c}0.01579^{* * *} \\
(0.0745)\end{array}$ & $\begin{array}{c}0.0192^{* * *} \\
(0.0071)\end{array}$ & $\begin{array}{c}0.0486^{* * *} \\
(0.0814)\end{array}$ & $\begin{array}{c}0.0365^{* * *} \\
(0.0073)\end{array}$ \\
\hline EL & $\begin{array}{l}-0.0054 \\
(0.0086)\end{array}$ & $\begin{array}{c}0.0045^{* * *} \\
(0.0021)\end{array}$ & $\begin{array}{c}-0.0169^{* * *} \\
(0.0179)\end{array}$ & $\begin{array}{c}0.0030^{* * * *} \\
(0.0017)\end{array}$ & $\begin{array}{c}0.0136^{* * *} \\
(0.0019)\end{array}$ & $\begin{array}{c}0.0011^{* * *} \\
(0.0017)\end{array}$ \\
\hline ER & $\begin{array}{c}0.0219^{* * *} \\
(0.0285)\end{array}$ & $\begin{array}{c}0.0065^{* * *} \\
(0.0070)\end{array}$ & $\begin{array}{l}-0.0048 \\
(0.0596)\end{array}$ & $\begin{array}{c}0.0031^{* * *} \\
(0.0571)\end{array}$ & $\begin{array}{c}0.0011 * * \\
(0.0065)\end{array}$ & $\begin{array}{c}0.0252^{* * *} \\
(0.0580)\end{array}$ \\
\hline GCS & $\begin{array}{l}0.0037 * \\
(0.0019)\end{array}$ & $\begin{array}{c}0.0068^{* * *} \\
(0.0047)\end{array}$ & $\begin{array}{c}0.0040^{* * * *} \\
(0.0398)\end{array}$ & $\begin{array}{c}-0.0034^{* * *} \\
(0.0381)\end{array}$ & $\begin{array}{c}0.0001 * * \\
(0.0044)\end{array}$ & $\begin{array}{c}0.0011^{* * *} \\
(0.0387)\end{array}$ \\
\hline $\begin{array}{l}\text { Cons } \\
R^{2}\end{array}$ & $\begin{array}{c}0.4068^{* * *} \\
0.4509\end{array}$ & $\begin{array}{c}0.3289^{* * *} \\
0.3341\end{array}$ & $\begin{array}{c}0.5253^{* * *} \\
0.1995\end{array}$ & $\begin{array}{c}0.3100^{* * *} \\
0.5623\end{array}$ & $\begin{array}{c}0.3365^{* * *} \\
0.4695\end{array}$ & $\begin{array}{c}0.5331^{* * *} \\
0.2941\end{array}$ \\
\hline
\end{tabular}

TABLE 3: Threshold estimate and threshold confidence interval.

\begin{tabular}{|c|c|c|c|c|c|c|c|c|c|}
\hline $\begin{array}{l}\text { Explanatory } \\
\text { variable }\end{array}$ & $\begin{array}{l}\text { Threshold } \\
\text { variable }\end{array}$ & $\begin{array}{c}\text { Threshold } \\
\text { number }\end{array}$ & $F$ value & $p$ value & $1 \%$ & $5 \%$ & $10 \%$ & Estimated value & $\begin{array}{c}\text { Confidence } \\
\text { interval }\end{array}$ \\
\hline \multirow{15}{*}{$Q$} & \multirow{3}{*}{$S$} & Single threshold & $13.50^{* * *}$ & 0.000 & 13.341 & 11.850 & 10.426 & 0.281 & {$[0.264,0.297]$} \\
\hline & & Double threshold & $10.00^{* *}$ & 0.019 & 11.550 & 10.611 & 7.689 & 0.471 & {$[0.449,0.496]$} \\
\hline & & Triple threshold & $7.30^{*}$ & 0.062 & 9.074 & 7.663 & 6.518 & 0.531 & {$[0.496,0.571]$} \\
\hline & \multirow{3}{*}{ E } & Single threshold & $8.020^{*}$ & 0.090 & 9.093 & 9.051 & 7.897 & 0.242 & {$[0.232,0.445]$} \\
\hline & & Double threshold & $11.550^{*}$ & 0.068 & 13.715 & 10.716 & 7.831 & 0.342 & {$[0.251,0.543]$} \\
\hline & & Triple threshold & $9.320^{*}$ & 0.062 & 17.727 & 7.189 & 5.505 & 0.516 & {$[0.472,0.527]$} \\
\hline & \multirow{3}{*}{$G$} & Single threshold & $13.920^{* *}$ & 0.060 & 26.270 & 15.987 & 10.286 & 0.271 & {$[0.254,0.281]$} \\
\hline & & Double threshold & $10.820^{* *}$ & 0.060 & 21.947 & 12.091 & 9.514 & 0.324 & {$[0.281,0.581]$} \\
\hline & & Triple threshold & 1.740 & 0.880 & 30.205 & 14.560 & 10.049 & 0.423 & {$[0.397,0.449]$} \\
\hline & \multirow{3}{*}{ C } & Single threshold & $10.550^{*}$ & 0.066 & 21.748 & 11.520 & 9.766 & 0.256 & {$[0.222,0.278]$} \\
\hline & & Double threshold & $10.240^{* *}$ & 0.028 & 12.097 & 9.617 & 8.081 & 0.333 & {$[0.310,0.352]$} \\
\hline & & Triple threshold & $15.950^{*}$ & 0.054 & 17.349 & 16.561 & 11.507 & 0.5095 & {$[0.489,0.547]$} \\
\hline & \multirow{3}{*}{$H$} & Single threshold & $4.130^{* *}$ & 0.03 & 8.916 & 7.297 & 7.023 & 0.346 & {$[0.255,0.391]$} \\
\hline & & Double threshold & $2.320^{*}$ & 0.08 & 17.136 & 11.319 & 8.222 & 0.452 & {$[0428,0.469]$} \\
\hline & & Triple threshold & $1.320^{*}$ & 0.09 & 14.825 & 10.186 & 8.965 & 0.497 & {$[0.484,0.507]$} \\
\hline
\end{tabular}

Note: (1) the critical value and $p$ value are obtained by using Bootstrap repeated 500 times; $(2)^{* * *},{ }^{* *}$, and ${ }^{*}$ represent significant correlations at $1 \%, 5 \%, 10 \%$ confidence levels, respectively.

economic growth, cultural heritage, and institutional system. All variables were significant. The second step is to understand whether the estimated threshold is equal to the true value. The threshold estimate and the corresponding confidence interval are shown in Table 3.

The results of the threshold regression are shown in Table 4. Combined with the threshold values presented in Table 3, it can be inferred that the ecological civilization construction shows a nonlinear relationship with social development, green environment, economic growth, cultural heritage, and institutional system.
(1) Results show that at the confidence levels of $1 \%, 5 \%$, and $10 \%$, social development was significantly related to the construction of ecological civilization. The highest level of ecological civilization construction was achieved when the Social Development Index went below 0.81 . When the level of social development was between 0.281 and 0.471 , the impact on ecological civilization was still positive, but it was weaker than the previous stage. When the level of social development was between 0.471 and 0.531 , the influence on the construction of ecological 
TABLE 4: Threshold regression results.

\begin{tabular}{lccccc}
\hline & $S$ & $E$ & $G$ & $C$ & $H$ \\
\hline$c$ & $0.328^{* * *}$ & $0.245^{* * *}$ & $0.301^{* * *}$ & $0.374^{* * *}$ & $0.334^{* * *}$ \\
PD & $0.049^{* * *}$ & $0.012^{*}$ & $0.003^{*}$ & 0.008 & -0.001 \\
CLR & $-0.001^{* * *}$ & $-0.001^{* * *}$ & $-0.001^{* *}$ & $0.006^{*}$ & $-0.010^{* * *}$ \\
PPI & 0.049 & $0.155^{* *}$ & $0.138^{*}$ & 0.006 & 0.009 \\
AQ & $0.027^{* *}$ & $0.145^{* * *}$ & $-0.254^{* * *}$ & 0.024 & $0.001^{*}$ \\
IST & $0.051^{*}$ & $0.057^{*}$ & $0.308^{*}$ & $0.090^{* * *}$ & $0.114^{* * *}$ \\
EC & $-0.062^{* *}$ & $-0.078^{* * *}$ & $-0.145^{* * *}$ & $-0.036^{*}$ & $-0.011^{* * *}$ \\
WCQ & 0.002 & $0.069^{* * *}$ & $0.044^{* *}$ & $0.088^{* * *}$ & $0.041^{*}$ \\
EL & $0.029^{* * *}$ & $0.033^{* * *}$ & $0.003^{* * *}$ & $0.008^{*}$ & $0.030^{* * *}$ \\
ER & $0.043^{* * *}$ & $0.038^{* * *}$ & $0.026^{* *}$ & $0.006^{* * *}$ & $-0.086^{*}$ \\
GCS & $0.002^{*}$ & $0.002^{*}$ & $0.004^{* * *}$ & 0.002 & $-0.002^{*}$ \\
$\alpha \_1$ & $0.278^{* * *}$ & $0.2901^{* * *}$ & $-0.386^{* * *}$ & 0.0632 & $0.212^{* * *}$ \\
$\alpha \_2$ & $0.232^{* * *}$ & $0.356^{* * *}$ & $-0.322^{* * *}$ & $0.102^{* *}$ & $0.258^{* * *}$ \\
$\alpha \_3$ & $0.198^{* * *}$ & $0.310^{* * *}$ & $0.299^{* * *}$ & $0.144^{* * *}$ & $0.198^{* * *}$ \\
$\alpha \_4$ & $0.224^{* * *}$ & $0.245^{* * *}$ & $0.261^{* * *}$ & $0.175^{* * *}$ & $0.211^{* * *}$ \\
$F$ value & $9.960^{* * *}$ & $18.110^{* * *}$ & $9.460^{* * *}$ & $11.250^{* * *}$ & $11.74^{* * *}$ \\
$R^{2}$ & $0.328^{* * *}$ & $0.245^{* * *}$ & $0.301^{* * *}$ & $0.374^{* * *}$ & $0.334^{* * *}$ \\
\hline$* * *{ }^{* *}$, and ${ }^{*}$ represent significant correlations at $1 \%, 5 \%$, and $10 \%$ con- \\
fidence levels, respectively. & & &
\end{tabular}

civilization was still weakening, and when the level of social development was more than 0.531 , its promoting effect on the structure of ecological civilization began to strengthen. At the initial stage of social development, there were shortages in medical care, electricity consumption, and public infrastructure construction in China, the construction of social development was accelerated and the structure of medical facilities and public infrastructure was improved. As a result, the urban unemployment rate decreased, residents' living and consumption ability improved, and social development gradually stabilized. The growth rate decreased slightly; however, the growth rate of the social development level was raised again under the influence of the continuous improvement of China's ecological civilization construction.

(2) The green environment had the most significant influence on the construction of ecological civilization, which was influenced by the confidence levels of $1 \%$ and $5 \%$. When the green environment passed through the three inflection points of $0.242,0.342$, and 0.516 , it promoted the construction of ecological civilization. As it embodies the ecological environment such as atmosphere, water, and land, the green environment also restricts the development of the economy and society. In the initial stage of construction and development, environmental resources played an increasing role in promoting ecological civilization; however, the continuous consumption of energy caused severe damage to resources and the environment, exacerbated environmental problems in China, and led to a gradual decline in the role of environment in promoting the construction of ecological civilization. Therefore, awareness on protecting the environment has been raised. The treatment rate of urban sewage and garbage increased year by year, but because of the difficulty of pollution control, a long treatment period, and high cost, a decline remained in the growth rate of the environmental index.

(3) The influence of economic growth on the construction of ecological civilization was significant at the $10 \%$ level and showed a U-shaped nonlinear relationship. When the economic growth was less than 0.271 , the construction of ecological civilization was restrained. When the economic growth was more than 0.271 and less than 0.324 , the inhibitory effect was weakened. When the economic growth was more than 0.324 , the inhibitory effect gradually changed into a promotive effect, and when it passed the inflection point of 0.423 , the stimulative effect increased gradually. In the early stages of economic development, there was a sole focus on economic growth with high efficiency and a disregard for the damage caused to the environment, which led to the inhibition of the construction of ecological civilization and slowed down the speed of economic growth. After state intervention and regulation, investment in science and technology increased. With the promotion of energy-saving technology, China's energy consumption per unit GDP decreased from 64.44 tons of standard coal/10000 yuan in 2000 to 46.4 tons of standard coal/10000 yuan in 2018. With the environmental loss caused by economic growth reduced, China's economy transformed into a quality-oriented green economy model, which played a role in promoting the construction of ecological civilization.

(4) Cultural inheritance had a positive nonlinear relationship with the construction of ecological civilization. The nonlinear relationship had a significant influence on the confidence levels of $5 \%$ and $10 \%$, and the cultural inheritance had only crossed the double threshold. When cultural heritage passed through 0.256 and 0.333 to the inflection point of 0.510 , the positive promotion level of ecological civilization construction increased gradually, which showed that the development of culture contributed to the construction of ecological civilization in China, but the promotion effect was not obvious. Culture was an integral part of China's development. By 2018, China had become the country with the largest number of intangible cultural heritages in the world. However, due to the large number of people in China, significant regional differences, and uneven levels of education, the protection and popularization of the construction of ecological civilization in China were different, resulting in the development of cultural inheritance having less influence on the structure of ecological civilization in China.

(5) The system had a positive effect on the construction of ecological civilization at the confidence levels of $5 \%$ and $10 \%$, but the system only had a double threshold. When the system reached the inflection 
point of 0.497 through 0.346 and 0.452 , the positive promoting effect increased initially and then decreased. From the above analysis, it can be seen that the system played a specific role in promoting and regulating the construction of ecological civilization in time and space and controlled the development of the structure of ecological civilization through legislation, the release of government policies, and public participation to avoid the system loss. However, because of the lag in the local government policy, the construction of the system had little effect on the development of ecological civilization.

\section{Discussion}

4.1. Discussion of the Results. This paper studies the law of space-time differentiation, the characteristics of regional coordination, and the influence mechanism of the construction of ecological civilization in China. It is found that the eastern part of China has the best level of ecological civilization construction, among which the economic index is the highest. As the coastal area of China, the eastern part has convenient transportation, a strong resource base, and frequent international trade. Some of the indicators were outstanding, for example, the urbanization rate was high. The local legislation and government information disclosure system were relatively sound; thus, a large number of talents flowed to the eastern region, which led to the development of the local society and economy. In addition, with more institutions of higher learning, residents have a higher level of education. However, due to its developed industry and large energy consumption per unit GDP, the environmental index was the lowest, the air quality was poor, and the environmental problems were serious.

The development of ecological civilization in the central and northeast regions of China was relatively general, and the development of the central region had changed considerably. The early economic development of the central region benefited from the inheritance of industrial transfer in the eastern region, and its development model was limited. Subsequently, national government policies were introduced one after another to increase economic mobility, and the growth rate of per capita GDP was prominent. Gradually, a "two-engine" model of economic development in the eastern and central regions was formed. The urban unemployment rate dropped, and social development gradually stabilized, thus improving ecological civilization construction in the central region.

As an old industrial base, the northeast region was rich in mineral and oil resources, and its industrial structure was dominated by the secondary industry, which belonged to the resource-based economy. However, uneven development and utilization led to the low comprehensive utilization rate of industrial solid waste and the low treatment rate of garbage, leading to resource depletion, environmental pollution, economic decline, brain drain, and other problems and therefore resulted in a modest level of ecological civilization.

The western region was the region with the worst outcome of China's ecological civilization construction. It is located in the interior and has a complicated climate environment, a large ecological protection area, and the best air quality. Therefore, the environmental index was the highest. It has a unique regional western culture. The number of cultural scenic spots is relatively large, but the consumption level of the residents is relatively low, and the construction of social infrastructure is relatively weak. As economic policies such as the "West-East natural gas transmission project" and the "West-East electricity transmission project" have been implemented, the rate of economic growth has increased substantially; however, its base is weak and is still different from other regions, resulting in a poor ecological civilization construction level.

4.2. Research Innovation. After consulting extensive literature, this paper found that the indicators of ecological civilization construction mainly focused on land space, environment, resources, economy, society, and system. With the development of the economy, the measurement of ecological civilization was not only limited to the existing research but also formed a complex multisystem. Therefore, this paper reintegrates the system of land space, resources, and environment. At the system level, the legal index is added, and according to the overall development status, the cultural system is added to the original system with cultural and intangible heritage, education level and other indicators were added to fill it. Finally, the construction of ecological civilization was divided into five levels: society, economy, environment, culture, and system.

In terms of research methods, there have been few methods to measure regional coordination and intraregional system coordination. Therefore, this paper started with the triangles model principles and moved to the pentagon model along the research process. The pentagon model not only determines the coordination degree of the regional ecological civilization construction in China but also directly reflects the coordination degree and deviation degree of each subsystem of the local ecological civilization. At the same time, to better promote the development of ecological civilization construction in China, after exploring the law of space-time evolution, this paper analyzed the influencing factors of ecological civilization construction with the help of the panel threshold model to deepen the significance of the article and widen the scope of the study.

4.3. Research Limitation. This study aims to improve and to optimize the relationship between human beings and nature. In essence, this research attempts to conform to a new pattern of economic development under the new normal, to meet people's new expectations for a better life, and to provide a new path for the sustainable development of all countries. However, when evaluating the construction of ecological civilization, attention should not only be paid to the macroscale and medium-scale but also to the microscale, such as "the construction of civilized ecological villages" and "the construction of ecological civilized communities."

Additionally, the lag issues in the system implementation have been overlooked in this research. These problems will affect the evaluation results of the structure of ecological 
civilization in different degrees, which will need to be taken into account to eliminate errors in the future. Also, though this paper evaluates the space-time distribution characteristics and influencing factors of ecological civilization construction, the system coordination and future development forecast of ecological civilization construction need to be further studied.

\section{Conclusion}

In this study, the spatiotemporal distribution of ecological civilization construction in 31 provinces, cities, and autonomous regions in China from 2000 to 2018 and its natural and social influencing factors were analyzed using the pentagon model and panel threshold model. The following conclusions were drawn:

(1) During the study period, China's ecological civilization construction as a whole increased from 12.07 in 2000 to 14.17 in 2018. The spatial differentiation pattern changed from environment >society $>$ economy $>$ system $>$ culture to environment $>$ society $>$ economy $>$ system $>$ culture in western China.

(2) The regional coordination degree was the highest in the eastern regions, followed by central, northeastern, and western regions. The intraprovincial coordination degree was unevenly distributed among five components in 2000-2008 and shifted toward the environment, economy, and society components. In 2018, the degrees of deviation in the regions decreased, the coordination among them strengthened, and they concentrated in the two categories of environment and society.

(3) Population density, consumption ability, environmental investment, air quality, technology input, energy consumption, world nonheritage quantity, educational level, environmental regulations, and government information disclosure have significant impacts on ecological civilization construction, social development, green environment, economic growth, cultural heritage, and institutional systems. Technology input had the largest influence followed by energy consumption. The influence of government information disclosure was the least.

\section{Data Availability}

Data are available on request.

\section{Conflicts of Interest}

There are no conflicts of interest to declare.

\section{Acknowledgments}

This research study was supported by the National Social Science Foundation of China (Grant no. 14ZDB130) and Liaoning Province Social Science Planning Fund Project (Grant no. L15BJY017). The authors would like to thank all experts for their contributions to the study of China's ecological civilization construction.

\section{References}

[1] H. Pang, Problems and Countermeasures of Ecological Yunnan Construction. Yunnan, Kunming University of science and technology, Yunnan, China, 2015.

[2] M. C. Liu, N. Su, and F. Lun, "An integrated indicator on regional ecological civilization construction," Acta Ecologica Sinica, vol. 34, no. 1, pp. 97-104, 2014.

[3] H. M. Li, Research on the Relationship between Ecological Civilization Construction and Economic Development in Western China, Southwest University of Finance and Economics Press, Chengdu, China, 2013.

[4] M. C. Yu, "Ecological civilization is the fourth civilization of human beings," Green Leaf, vol. 11, pp. 20-21, 2006.

[5] L. Zhou, H. Mu, B. Wang, B. Yuan, and X. Dang, "Evaluating urban community sustainability by integrating housing, ecosystem services, and landscape configuration," Complexity, vol. 2020, Article ID 3460962, 14 pages, 2020.

[6] Z. L. Li, X. Gong, and J. Chen, "Functional requirements of systems for visualization of sustainable development goal (SDG) indicators," Journal of Geovisualization \& Spatial Analysis, vol. 4, no. 1, 2020.

[7] Y. Zhang, J. Fan, and S. Chen, "A quantitative evaluation on ecological city construction level of urban agglomeration in the middle reaches of Yangtze river," Journal of Coastal Research, vol. 98, no. 1, p. 300, 2019.

[8] X. Wang and X. Chen, "An evaluation index system of China's development level of ecological civilization," Sustainability, vol. 11, 2019.

[9] L. Zhou, C. Zhou, L. Che, and B. Wang, "Spatio-temporal evolution and influencing factors of urban green development efficiency in China," Journal of Geographical Sciences, vol. 30, no. 5, pp. 724-742, 2020.

[10] Z. F. Mi, C. Zhou, F. F. Zhu, and G. Zeng, "The path dependence and relationship change of ecological civilization construction: based on the panel data analysis of prefecturelevel cities in the Yangtze River Economic Belt from 2003 to 2015," Geographical Research, vol. 37, no. 10, pp. 1915-1926, 2018.

[11] H. C. Zhou, Z. H. Song, Y. F. Liu, and X. L. Zhang, "Evaluation, comparison and improvement of ecological civilization construction evaluation index system," Eco-Economy, vol. 35, no. 8, pp. 213-222, 2019.

[12] Z. B. Deng, S. W. Zong, and C. W. Su, "Research on coupling coordination development between ecological civilization construction and new urbanization and its driving forces in the Yangtze River economic zone," Economic Geography, vol. 39, no. 10, pp. 78-86, 2019.

[13] G. H. Bi, Q. Y. Yang, and S. Liu, "Coupling and coordinated development of ecological civilization construction and urbanization in China province," Economic Geography, vol. 37, no. 1, pp. 50-58, 2017.

[14] P. Yang, "Evaluation of ecological civilization development in the post-olympic times," Applied Ecology and Environmental Research, vol. 17, no. 4, 2019.

[15] B. G. Wang and X. H. Liu, "Evaluation of ecological civilization construction in Xinjiang based on PSR model," Acta Agriculturae Jiangxi, vol. 31, no. 3, pp. 135-147, 2019.

[16] J. F. Sun, W. S. Qin, and H. Y. Sun, "Evaluation system and measurement of marine ecological civilization in coastal cities of China," Economic Geography, vol. 38, no. 8, pp. 19-28, 2018.

[17] B. Hu, F. Wang, and J. Y. Li, "Efficiency evaluation on urban eco-civilization construction via SBM-Undesirable Model- 
Taking Tianjin as an example," Resources and Environment in Arid Areas, vol. 29, no. 4, pp. 13-18, 2015.

[18] L. Zhang, J. Yang, D. Li et al., "Evaluation of the ecological civilization index of China based on the double benchmark progressive method," Journal of Cleaner Production, vol. 222, no. 10, pp. 511-519, 2019.

[19] Y. X. Zhang, J. H. Cheng, and Z. C. Xu, "Evaluation and improvement of regional ecological construction coordination in China," Population, Resources and Environment, vol. 29 , no. 6 , pp. 58-64, 2019.

[20] S. G. Feng, C. Zhang, and Y. Cui, "Spatiotemporal differentiation of ecological civilization and its coordination degree in Hebei Province," Soil and Water Conservation Research, vol. 25, no. 1, pp. 364-375, 2018.

[21] X. J. Wu, Y. Peng, and X. Q. Wang, "The spatial-temporal evolution and driving factors of ecological civilization of 31 provincial administrative regions," Journal of Arid Land Resources and Environment, vol. 30, no. 8, pp. 1-9, 2016.

[22] T. Liu, J. Li, and J. Chen, "Urban ecological efficiency and its influencing factors-a case study in Henan Province, China," Sustainability, vol. 11, 2019.

[23] X. E. Qu, "Regional differentials and influence factors of ecoefficiency in China: an empirical analysis based on the perspective of spatio-temporal differences," Resources and Environment in the Yangtze Basin, vol. 27, no. 12, pp. 2673-2683, 2018.

[24] L. S. Zhong, X. Y. Ma, and Y. X. Zeng, "Research progress and Prospect of ecotourism in China," Progress in Geosciences, vol. 35, no. 6, pp. 679-690, 2016.

[25] P. Ren, X. Liu, and J. Liu, "Research on construction of indicator system for evaluation of the ecological civilization education in Chinese Universities," Cognitive Systems Research, vol. 52, pp. 747-755, 2018.

[26] F. Wang, Z. L. Shi, J. C. Wang, C. J. Song, and K. T. Dang, "Thinking on promoting green development of agriculture from the perspective of ecological civilization construction," China's Agricultural Resources and Zoning, vol. 39, no. 8, pp. 17-22, 2018.

[27] China Statistical Yearbook on Enviroment, China Environmental Statistics Yearbook, China Statistics Press, Beijing, China, 2018.

[28] China Environmental Editorial Service, China's Environmental Yearbook, China Environmental Editorial Press, Beijing, China, 2018.

[29] China Law Society, Law Yearbook of China. China Law Yearbook, China Law Society, Beijing, China, 2018.

[30] China Procuratorial Press, Editorial Department of China Procuratorial Yearbook of the Supreme People's Procuratorate. Procuratorial Yearbook of China, China Procuratorial Press, Beijing, China, 2018.

[31] G. B. Li and Y. P. Tian, "Validity analysis of tourism resources competitiveness and tourism development level in pearl river delta," Economic Geography, vol. 39, no. 3, pp. 218-224, 2019.

[32] X. Y. Wang and W. L. Zhu, "Evaluation of rural tourism competitiveness and analysis of obstacles in Shandong Province," Geographic Science, vol. 39, no. 1, pp. 150-158, 2019.

[33] P. Liu, L. F. Wang, and Y. Xu, "DEA cross efficiency aggregation method based on "expert scoring method," Science and Technology Management Research, vol. 39, no. 2, pp. 248-253, 2019.

[34] B. E. Hansen, "Threshold effects in non-dynamic panels: estimation, testing, and inference," Journal of Econometrics, vol. 93, no. 2, pp. 345-368, 1999. 